\title{
Correction to: Pre-Field Screening Protocols for Heat-Tolerant Mutants in Rice
}

\section{Correction to:}

F. Sarsu et al., Pre-Field Screening Protocols

for Heat-Tolerant Mutants in Rice, https://doi.org/10.1007/978-3-319-77338-4

The book was inadvertently published with several mistakes, which have now been corrected.

Copyright page: The affiliations of the authors Brian P. Forster and Ivan Ingelbrecht have been corrected to:

Brian P. Forster

Plant Breeding and Genetics Laboratory,

Joint FAO/IAEA Division

International Atomic Energy Agency

Vienna, Austria

Ivan Ingelbrecht

Plant Breeding and Genetics Laboratory,

Joint FAO/IAEA Division

International Atomic Energy Agency

Vienna, Austria

Preface: The second author name 'Priyanka Das' has been deleted.

The updated online version of the chapter can be found at 
Chapter 2: The legends to Figure 2.8 and Figure 2.9 have been interchanged. The correct legends are:

Fig. 2.8 Heat stress phenotyping in growth chambers at $35.0-39.0{ }^{\circ} \mathrm{C} / 28{ }^{\circ} \mathrm{C}$ (day/ night) for 6-4/18-20 h for 6-4 days 80\% relative humidity (a, c and d). Heat stress application in growth chamber with pots, trays and hydroponics. (b) Enlarged view of panicles (Pictures from Jawaharlal Nehru University, India)

Fig. 2.9 Illustration of heat stress treatments on rice at the flowering stage

Figure 2.8 has been replaced with a new version. 